\title{
Synthesis, Crystal Structure, Mesophase Behaviour and Optical Property of Azo-ester Bridged Compounds
}

\author{
M. R. Karim ${ }^{1 *}$, M. R. K. Sheikh², M. S. Islam ${ }^{1}$, N. M. Salleh ${ }^{3}$, R. Yahya ${ }^{3}$ \\ ${ }^{1}$ Department of Chemistry, Rajshahi University, Rajshahi 6205, Bangladesh \\ ${ }^{2}$ Department of Applied Chemistry and Chemical Engineering, Rajshahi University, Rajshahi 6205, \\ Bangladesh \\ ${ }^{3}$ Department of Chemistry, University of Malaya, Kuala Lumpur 50603, Malaysia
}

Received 29 May 2019, accepted in final revised form 31 July 2019

\begin{abstract}
Azo-ester mesogen containing two liquid crystalline compounds C1-C2 having polymerizable acrylate functional group as the terminal were designed and synthesized. The chemical structures and purity of the synthesized compounds were confirmed by different spectroscopic techniques such as FT-IR, ${ }^{1} \mathrm{H}$ NMR and ${ }^{13} \mathrm{C}$ NMR. X-ray crystal structure showed that compound $\mathbf{C} 1$ exhibited more stable $E$ configuration with two bulky groups in the opposite sides of the $\mathrm{N}=\mathrm{N}$ double bond motifs. The 1, 2-diphenyldiazene fragment in the structure of $\mathbf{C 1}$ is essentially planar with RMS deviation from planarity of $0.0555 \AA$. Analysis of the crystal packing of compound $\mathbf{C 1}$ revealed its intriguing supramolecular sheet-like multilayer molecular packing stabilized by $\mathrm{C}-\mathrm{H}$... O interaction involving the phenyl and acryloyl hydrogen with the carbonyl oxygen and alkoxy oxygen atoms. Thermogravimetric investigation demonstrated that both of the compounds exhibited excellent thermal stability and their thermal degradation was influenced by the terminal substituent. The DSC and POM studies confirmed that compounds C1-C2 exhibited enantiotropic liquid crystalline mesophase behaviour. Optical investigations demonstrated that both of the compounds showed strong absorption band around 300-420 nm and exhibited blue fluorescence emission.
\end{abstract}

Keywords: Azo mesogen; Crystal structure; Mesophase; Optical property.

() 2019 JSR Publications. ISSN: 2070-0237 (Print); 2070-0245 (Online). All rights reserved.

doi: http://dx.doi.org/10.3329/jsr.v11i3.41578 J. Sci. Res. 11 (3), 383-395 (2019)

\section{Introduction}

Liquid crystalline (LC) materials are a class of compounds which exhibit intermediate characteristic between crystalline solid and isotropic liquid. These materials have extensively been studied due to their substantial applications in electro-optical flat panel display devices, laptop computers, speedometers, vehicle clocks, spectrometers, mobile phones, chemical and biological sensors, actuators, and so on [1-3]. In the recent years, the quest of new LC materials has enormously increased due to their slim shape, low

\footnotetext{
Corresponding author: rabiul30@ru.ac.bd
} 
weight, low-voltage operation and low power consumption [4]. As a result, significant efforts have been provided for the systematic investigation of the relationships between molecular structure and liquid crystallinity.

Thermotropic calamitic LC molecules mainly comprise of aromatic molecular core connected by different linking groups, e.g., stilbene $(-\mathrm{CH}=\mathrm{CH}-)$, azomethine $(-\mathrm{CH}=\mathrm{N}-)$, azo $(-\mathrm{N}=\mathrm{N}-)$, ester $(-\mathrm{COO}-)$ and acetylene $(-\mathrm{C} \equiv \mathrm{C}-)[5,6]$. The selection of linking groups in LC compounds is very crucial due to the overall molecular length as well as polarizable anisotropy which may improve the stability of the compounds and the temperature range of the mesophase [7]. Azo-chromophore containing materials either low molecular weight or polymeric in nature, are versatile and promising class of compounds due to their unique electrical, optical and mechanical properties. The most startling and intriguing property of all azobenzenes (and their derivatives) is the efficient and fully reversible photoisomerization which occurs upon absorption of a photon. The photochemical properties of azo compounds make them potential in variety of optical and optoelectronic applications such as, optical data storage, nonlinear optical devices, photo switching materials, LC display devices and so forth [8-15]. Over the last several decades, much efforts have been devoted to synthesis of azo compounds and study their properties due to the robust and versatile moieties of azo chromophore. Moreover, many mesogenic compounds containing azo central linkage have been studied as most of them exhibit LC properties above room temperature [7]. In addition, the photochromic azo group can be used to control phase behaviour and optical properties of LC materials [16]. Like azo $(-\mathrm{N}=\mathrm{N}-)$ linking group, ester $(-\mathrm{COO}-)$ group is also considered as a versatile and most commonly used linking unit in LC materials because it increases the polarisability of molecules and provides relatively stable mesophase. Consequently, the incorporation of azo together with ester linking groups in the mesogenic core of a LC compound could allow achieving an anticipated mesophase as well as multifunctional materials. On the other hand, detailed knowledge of molecular structure is inevitable for finding the structure-function relationships and for a systematic approach to the design of new compounds [17]. Single-crystal X-ray diffraction analysis reveals structural information including conformation, stereochemistry, intra- and intermolecular interactions that are in relation with optical properties as well as technical properties of azo compounds [18].

In recent years, many research groups have been working with azo-ester linked LC materials and their main target to study the effect of varying alkyl chain length, lateral substituents and terminal group on the thermal and mesomorphic behaviours [19-21]. Vora and Dixit [22] have reported a homologous series of LC compounds containing azoester linking groups and lateral substitution. Lai and Lin [23] have also synthesized azo mesogen containing compounds that show a variation of mesogenic behaviour with the length of alkyl chains. Imrie et al. have also reported some LC oligomers having azo linkage [24]. Recently, Naoum et al. [25,26] have synthesized some azo-ester linked LC compounds and studied the exchange effect of terminal substituent, inversion effect of ester group as well as the effect of lateral methyl group. Terminal electron-donating substituents containing compounds exhibited purely nematogenic behaviour depending on 
the alkoxy chain length whereas compounds bearing terminal electron-withdrawing substituents showed dimorphic and purely smectogenic (SmA) character. In our previous report, we have synthesized azo-ester mesogen containing LC compounds and investigated the effect of terminal electron withdrawing and donating substituents on crystal structure, mesophase formation, thermal and optical properties [27]. Single crystal X-ray study revealed that the terminal substituents have profound effect on crystal structure of the synthesized compounds. In addition, the thermal stability and mesophase formation were also greatly influenced by the terminal electron withdrawing and pushing substituents. In this report, we have described the synthesis and characterization of azoester bridged two new LC compounds containing butoxy $\left(-\mathrm{OC}_{4} \mathrm{H}_{9}\right)$ group as well as heavy halogen iodine (I) atom in one terminal and polymerizable acrylate functional group in the other terminal. We have also evaluated the effect of terminal substituents on crystal structure, thermal stability, mesophase formation and optical property.

\section{Experimental}

\subsection{Materials and measurements}

All the reagents and chemicals used in this study were of reagent grade and purchased from Merck, Acros Organics, Sigma-Aldrich, R \& M Chemicals, J. T. Baker and John Kollin Corporation. Solvents were dried by standard techniques and distilled prior to use. Other chemicals were used as received.

${ }^{1} \mathrm{H}$ and ${ }^{13} \mathrm{C}$ NMR spectra were recorded with a JEOL spectrometer $(400 \mathrm{MHz})$ in $\mathrm{CDCl}_{3}$ and DMSO-D 6 . FT-IR spectra $\left(4000-450 \mathrm{~cm}^{-1}\right)$ were taken on a PerkinElmer Spotlight 400 spectrometer with 16 scans using attenuated total reflectance (ATR) method and a resolution of $4 \mathrm{~cm}^{-1}$. Single crystal X-ray diffraction measurements of compounds were carried out using Bruker APEX-II CCD area detector equipped with the graphite monochromator at $140(2) \mathrm{K}$ with $\mathrm{Mo}-\mathrm{K}_{\alpha}$ radiations $(\lambda=0.71073 \AA)$. Structures were solved by the direct methods with full-matrix least-squares refinement on $\mathrm{F}^{2}$. Thermal decomposition temperature data were recorded on a SDT Q600 thermogravimetric analyser under nitrogen atmosphere at a heating rate of $20{ }^{\circ} \mathrm{C} \mathrm{min}{ }^{-1}$. The DSC measurements were conducted to study the thermal transitions of investigated compounds using a PerkinElmer DSC6 instrument at heating and cooling rates of $10{ }^{\circ} \mathrm{C} \mathrm{min}{ }^{-1}$ under nitrogen atmosphere. The LC phase behaviour was investigated using an Olympus BH-2 polarized optical microscope (POM) equipped with a Mettler Toledo hot stage FP-82. $\mathrm{UV}$-vis absorption and photoluminescence (PL) spectra in dilute $\mathrm{CHCl}_{3}$ solution $\left(5 \times 10^{-5}\right.$ M) were recorded on Cary $60 \mathrm{UV}$-vis and Cary Eclipse Fluorescence spectrophotometer.

\subsection{Preparation of azo-ester compounds}

Ethyl 4-[(4'-hydroxy)phenylazo]benzoate (1), ethyl 4-[4'-(6-hydroxyhexyloxy)phenylazo] benzoate (2), 4-[4'-(6-hydroxyhexyloxy)phenylazo] benzoic acid (3) and 4-[4'-(6acryloyloxyhexyloxy) phenylazo] benzoic acid (4) were prepared by the method described in the literatures $[28,29]$. 


\subsection{Synthesis of (E)-4-butoxyphenyl [4'- $\left\{4^{\prime \prime-(6-a c r y l o y l o x y) h e x y l o x y\} p h e n y l a z o] ~}\right.$ benzoate (C1)}

In a mixture of dry DMF and DCM (1:1), compound 4 (2.5623 g, $4.70 \mathrm{mmol}$ ), appropriate amount of 4-butoxyphenol (1.0228 g, $6.15 \mathrm{mmol})$ and catalytic amount of $N, N^{\prime}$ dimethylaminopyridine (DMAP) were dissolved and cooled in an ice bath. $N, N^{\prime}$ dicyclohexylcarbodiimide (DCC) (0.9762 g, $4.73 \mathrm{mmol})$ was dissolved in DCM (10 mL) and then poured slowly into the ice cold reaction mixture. The resultant mixture was cooled in an ice bath with stirring for $1 \mathrm{~h}$. After that, the reaction mixture was stirred for another $24 \mathrm{~h}$ at room temperature for completion of the reaction. Finally, the obtained solid was filtered out and the solvent was evaporated under reduced pressure. The crude product was crystallized from ethanol-water mixture followed by recrystallized twice from 2-propanol and obtained an orange-yellow crystalline solid compound, C1. Yield: $38 \%, T_{\mathrm{m}}=102-103{ }^{\circ} \mathrm{C}$; FT-IR $\left(\mathrm{cm}^{-1}\right): 2952,2878(\mathrm{C}-\mathrm{H}$, aliphatic), $1719(\mathrm{C}=\mathrm{O}$ in ester $)$, $1637(\mathrm{C}=\mathrm{C}$, vinyl), 1603, $1584(\mathrm{C}=\mathrm{C}$, aromatic), 1506, $1477(-\mathrm{N}=\mathrm{N}-), 1414,1404$, $1301,1274,1245,1187,1141,1077,1005,865,835 ;{ }^{1} \mathbf{H}$ NMR $\left(400 \mathrm{MHz}, \mathrm{CDCl}_{3}\right) \delta$

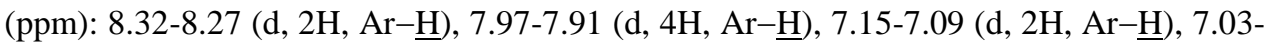
6.97 (d, 2H, Ar- $\underline{\mathrm{H}}), 6.95-6.89$ (d, 2H, Ar- $\underline{\mathrm{H}}), 6.43-6.35$ (d, 1H, $\left.-\mathrm{CH}=\mathrm{C}_{2}\right), 6.16-6.06$ (q, $\left.1 \mathrm{H},-\mathrm{C} \underline{\mathrm{H}}=\mathrm{CH}_{2}\right), 5.84-5.77\left(\mathrm{~d}, 1 \mathrm{H},-\mathrm{CH}=\mathrm{CH}_{2}\right), 4.21-4.13\left(\mathrm{t}, 2 \mathrm{H}, \mathrm{C}_{3} \mathrm{H}_{7}-\underline{\mathrm{C}}_{2} \mathrm{O}-\mathrm{Ar}-\right)$, 4.08$4.01\left(\mathrm{t}, 2 \mathrm{H},-\mathrm{Ar}-\mathrm{OC}_{2}-\right), 3.99-3.92$ (t, $\left.2 \mathrm{H},-\mathrm{CH}_{2}-\mathrm{OCO}-\right)$, 1.88-1.67 (m, 6H, $-\mathrm{CH}_{2}-$ ), 1.61-1.41 (m, 6H, $\left.-\mathrm{C}_{2}-\right)$, 1.01-0.94 (t, 3H, $\left.-\mathrm{C}_{3}\right) ;{ }^{13} \mathbf{C ~ N M R}\left(400 \mathrm{MHz}, \mathrm{CDCl}_{3}\right) \delta$ (ppm): 166.6 (-O-CO-), 165.2 (Ar-O-CO-Ar), 162.5, 157.1, 155.8, 147.2, 144.2, 131.3, $130.9,128.7,125.4,122.6,122.4,115.2$, ( $\mathrm{Ar}-\underline{\mathrm{C}}), 131.3\left(-\mathrm{CH}=\underline{\mathrm{CH}}_{2}\right), 128.7\left(-\underline{\mathrm{CH}}=\mathrm{CH}_{2}\right)$, $68.3\left(\mathrm{Ar}-\mathrm{O}_{\underline{C}} H_{2}-\right), 68.2\left(\mathrm{Ar}-\mathrm{O}_{\underline{C}} H_{2}-\right), 64.6\left(-\mathrm{H}_{2} \underline{\mathrm{C}}-\mathrm{OCO}-\right)$ 31.5, 29.2, 28.7, 25.8, 19.4, 13.9 (Aliphatic- $\underline{\mathrm{C}}$ ).

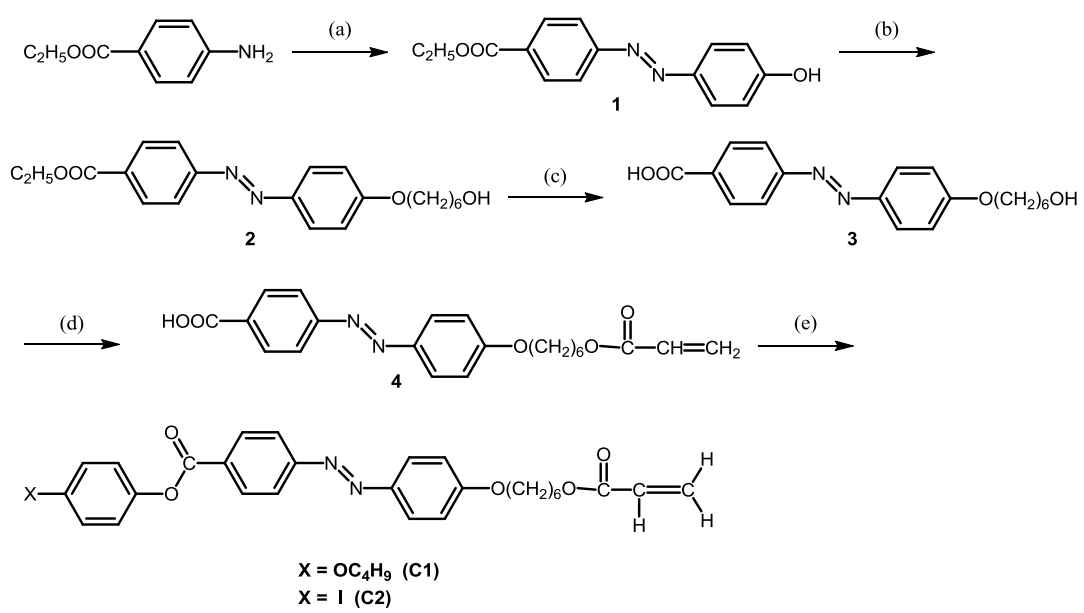

Scheme 1. Reactions and reagents: (a) $\mathrm{NaNO}_{2}, \mathrm{HCl}$, phenol, $\mathrm{NaOH}, 0-5{ }^{\circ} \mathrm{C}$; (b) 6-chlorohexanol, $\mathrm{K}_{2} \mathrm{CO}_{3}$, $\mathrm{KI}$, heated in dry DMF, $8 \mathrm{~h}, 130{ }^{\circ} \mathrm{C}$; (c) Ethanol, $\mathrm{KOH}$, refluxed $4 \mathrm{~h}$, acidified with $\mathrm{HCl}$; (d) acryloyl chloride, TEA, stirred at $0{ }^{\circ} \mathrm{C}$ in THF, $1 \mathrm{~h}$ and at $25^{\circ} \mathrm{C}, 24 \mathrm{~h}$; (e) substituted phenol, DCC, DMAP, stirred at $0{ }^{\circ} \mathrm{C}$ in dry DMF and DCM, $1 \mathrm{~h}$, and at $25^{\circ} \mathrm{C}, 24 \mathrm{~h}$. 


\subsection{Synthesis of (E)-4-iodo [4'- $\left\{4^{\prime \prime}-(6\right.$-acryloyloxy)hexyloxy\}phenylazo]benzoate (C2)}

The synthesis of compound $\mathbf{C 2}$ was similar to that described for compound C1. 4-Iodo phenol was used instead of 4-butyloxy phenol in the reaction. Orange-yellow solid, Yield: $40 \%, T_{\mathrm{m}}=138-139{ }^{\circ} \mathrm{C}$; FT-IR $\left(\mathrm{cm}^{-1}\right): 2936,2855(\mathrm{C}-\mathrm{H}$, aliphatic), 1727, $1715(\mathrm{C}=\mathrm{O}$ in ester), $1635(\mathrm{C}=\mathrm{C}$, vinyl), 1599, $1580(\mathrm{C}=\mathrm{C}$, aromatic), 1502, $1480(-\mathrm{N}=\mathrm{N}-), 1463,1408$, 1297, 1250, 1194, 1167, 1142, 1071, 1054, 1000, 981, 857, 833; ${ }^{1} \mathbf{H}$ NMR (400 MHz, $\left.\mathrm{CDCl}_{3}\right) \delta(\mathrm{ppm}): 8.32-8.27(\mathrm{~d}, 2 \mathrm{H}, \mathrm{Ar}-\underline{\mathrm{H}}), 7.99-7.91(\mathrm{~d}, 4 \mathrm{H}, \mathrm{Ar}-\underline{\mathrm{H}}), 7.77-7.70(\mathrm{~d}, 2 \mathrm{H}$, $\mathrm{Ar}-\underline{\mathrm{H}}), 7.04-6.98(\mathrm{~d}, 4 \mathrm{H}, \mathrm{Ar}-\underline{\mathrm{H}}), 6.42-6.36\left(\mathrm{~d}, 1 \mathrm{H},-\mathrm{CH}=\mathrm{CH}_{2}\right), 6.17-6.07$ (q, $1 \mathrm{H}$, $\left.-\mathrm{C} \underline{\mathrm{H}}=\mathrm{CH}_{2}\right), 5.85-5.78\left(\mathrm{~d}, 1 \mathrm{H},-\mathrm{CH}=\mathrm{C}_{2}\right), 4.21-4.15\left(\mathrm{t}, 2 \mathrm{H}, \mathrm{C}_{3} \mathrm{H}_{7}-\mathrm{C}_{2} \mathrm{O}-\mathrm{Ar}-\right), 4.08-4.02$ (t, $\left.2 \mathrm{H},-\mathrm{Ar}-\mathrm{OCH}_{2}-\right), 1.89-1.67\left(\mathrm{~m}, 4 \mathrm{H},-\mathrm{C}_{2}-\right), 1.57-1.42\left(\mathrm{~m}, 4 \mathrm{H},-\mathrm{C}_{2}-\right) ;{ }^{13} \mathbf{C} \mathbf{~ N M R}$ $\left(400 \mathrm{MHz}, \mathrm{CDCl}_{3}\right) \delta$ (ppm): 166.5 (-O-CO-), 165.3 (Ar-O-CO-Ar), 162.2, 156.0, 151.2, 147.2, 138.8, 130.7, 130.1, 125.5, 124.0, 122.7, 115.2, 90.2 (Ar-C) 131.3 ($\left.\mathrm{CH}=\underline{\mathrm{CH}}_{2}\right), 128.7\left(-\underline{\mathrm{CH}}=\mathrm{CH}_{2}\right), 68.4\left(\mathrm{Ar}-\mathrm{OCH}_{2}-\right), 64.6\left(\mathrm{Ar}-\mathrm{OCH}_{2}-\right), 29.2,28.7,25.8$ (Aliphatic-C).

\section{Results and Discussion}

\subsection{Synthesis and structural characterization}

Scheme 1 outlines the synthetic route of compounds C1-C2. Both of the compounds were synthesized via azo-coupling, Williamson etherification, hydrolysis, condensation and finally Steglich esterification. The yellow to orange coloured crystalline products were obtained in fairly good yield (38-40\%). However, no significant effect of terminal groups was observed on yield of the final product. The synthesized LC compounds consist of polymerizable acrylate group at one end as well as butoxy and iodo substituents on the other terminal which is the main structural feature of the compounds. The structure and purity of the resulting new compounds were verified by spectroscopic methods (FT-IR, ${ }^{1} \mathrm{H}$ and $\left.{ }^{13} \mathrm{C} \mathrm{NMR}\right)$.

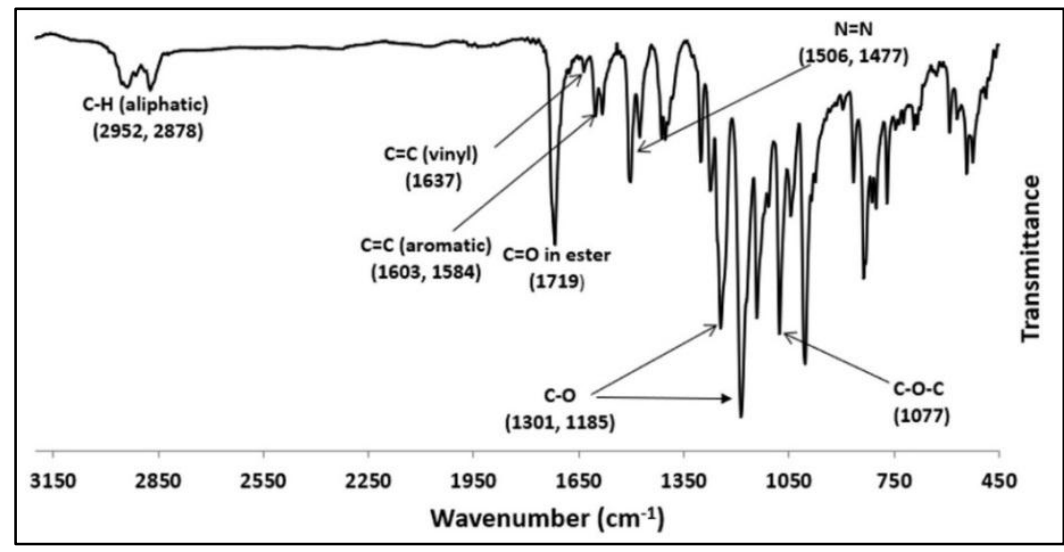

Fig. 1. FT-IR spectrum of compound $\mathbf{C 1}$. 
Fig. 1 depicts the FT-IR spectrum of LC compound $\mathbf{C 1}$ and shows different vibrational modes corresponding to the stretching and bending of various functional groups present in the molecule. A broad absorption band is assigned to aliphatic asymmetric and symmetric stretching vibration of methylene $\left(-\mathrm{CH}_{2}-\right)$ groups in the alkyl chain around 2952-2878 $\mathrm{cm}^{-1}$. A strong absorption band that is observed at $1719 \mathrm{~cm}^{-1}$ can be ascribed to the stretching of ester $(\mathrm{C}=\mathrm{O})$ group. The low intensity band at $1634 \mathrm{~cm}^{-1}$ is attributed to the stretching vibration for $\mathrm{C}=\mathrm{C}$ in the terminal acrylate functional group. Besides, the bands at 1603 and $1584 \mathrm{~cm}^{-1}$ can also be assigned to the stretching vibration of $\mathrm{C}=\mathrm{C}$ in aromatic ring. Two medium bands at 1506 and $1477 \mathrm{~cm}^{-1}$ are ascribed to the stretching vibration of $\mathrm{N}=\mathrm{N}$ bond. The strong bands at 1301 and $1185 \mathrm{~cm}^{-1}$ can be attributed to the stretching vibration for $\mathrm{C}-\mathrm{O}$ group. Moreover, strong absorption band at $1077 \mathrm{~cm}^{-1}$ is observed for stretching of $\mathrm{C}-\mathrm{O}-\mathrm{C}$ group. Fig. 2 shows ${ }^{1} \mathrm{H}$ NMR spectrum of LC compound $\mathbf{C 1}$ with molecular structure. The signal around $\delta 1.01-0.94 \mathrm{ppm}$ in the triplet form is observed due to methyl $\left(-\mathrm{CH}_{3}\right)$ protons of butoxy group. Multiplet peaks nearly $\delta 1.88-0.94 \mathrm{ppm}$ are attributed for methylene $\left(-\mathrm{CH}_{2}-\right)$ protons of butoxy group and alkyl chain. Three triplet signals around 4.21-3.92 ppm are ascribed for $-\mathrm{OCH}_{2}-$ alkoxy protons. Two doublets and a quartet which are characteristic vinylidene proton peaks of acrylate group observed about $\delta 6.42-5.77 \mathrm{ppm}$ [30]. The signals between $\delta 8.32-6.89 \mathrm{ppm}$ as doublet form are assigned to aromatic ring protons. Since compound C2 possess structural similarity with C1 except the terminal group, the FT-IR and NMR spectra of both compounds are almost similar.

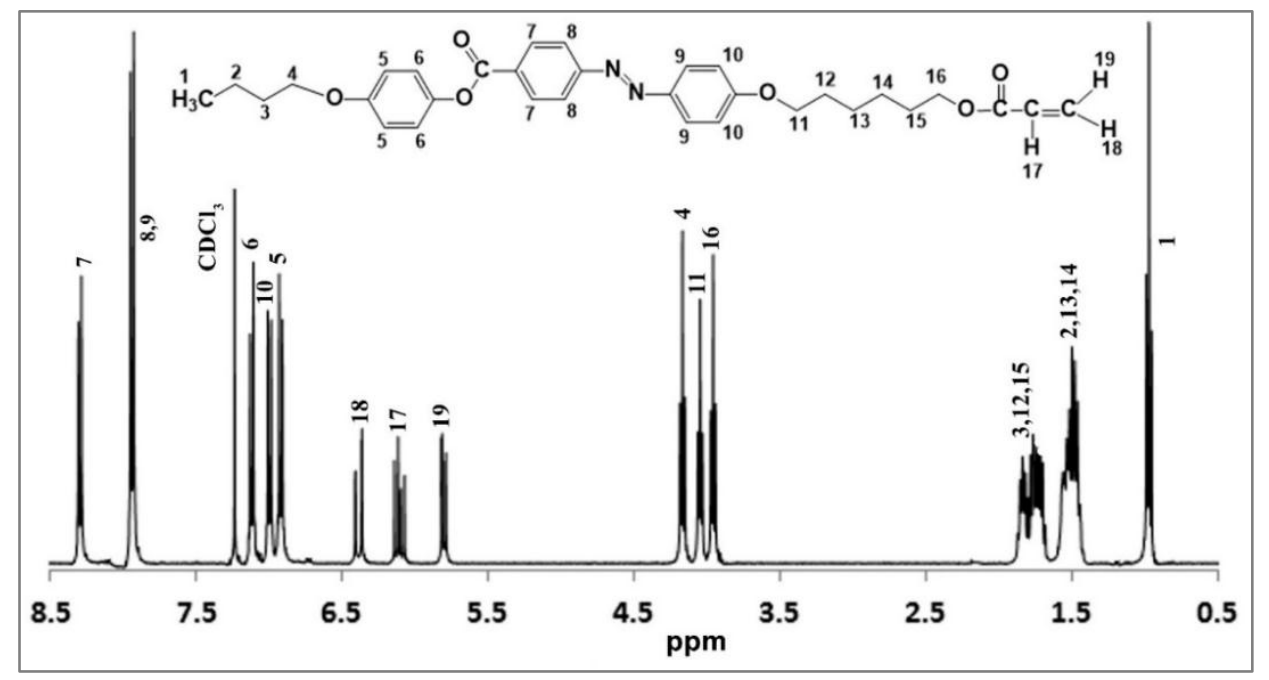

Fig. 2. ${ }^{1} \mathrm{H}$ NMR spectrum of compound $\mathbf{C 1}$. 


\subsection{Crystal structure}

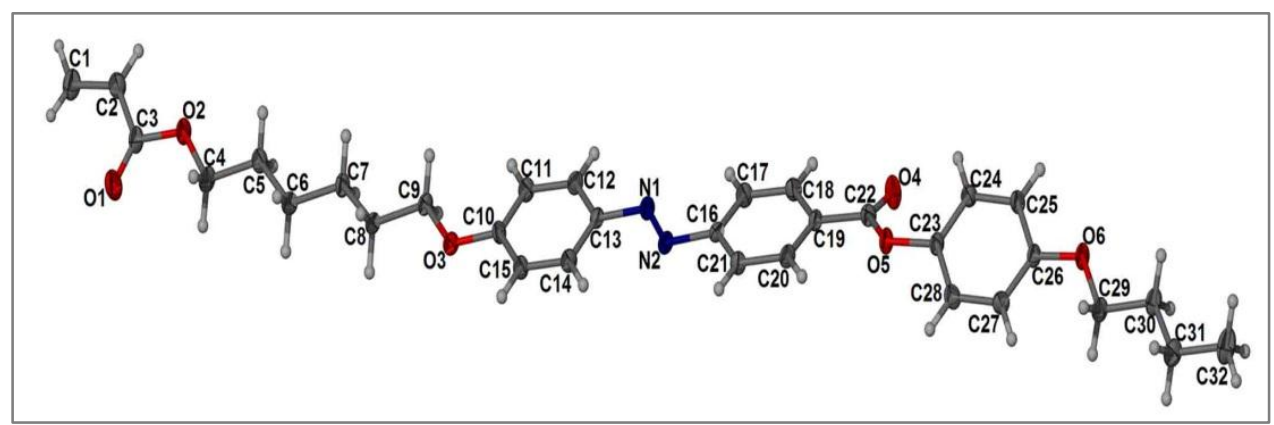

Fig. 3. The molecular structure of compound $\mathbf{C 1}$ with the atom-numbering scheme.

The molecular structure of compound $\mathbf{C 1}$ with atom-numbering scheme is depicted in Fig. 3 and the crystal structure is illustrated in Fig. 4. The crystal parameters, selected bond distances and bond angles of compound $\mathbf{C 1}$ are listed in Table S1 in the Supporting Information (SI). The bond length of azo unit $\mathrm{N}(1)-\mathrm{N}(2)$ (Table S1) of compound $\mathbf{C 1}$ is 1.269 (3) $\AA$ indicative of double-bond character [31]. It can be seen from Fig. 3 that the two bulky groups situated at the opposite sides of the azo $(-\mathrm{N}=\mathrm{N}-)$ group and this leads to formation of $E$ isomer which is more stable conformation of the compound. As compound C2 bears structural similarity except the terminal, it would exhibit analogous structural motif with the $E$ configuration at the $\mathrm{N}=\mathrm{N}$ double bond. The 1, 2-diphenyldiazene fragment in structure of compound $\mathbf{C 1}$ is essentially planar with RMS deviation from planarity of $0.0555 \AA$. Detail analysis of the crystal packing of compound $\mathbf{C 1}$ revealed its intriguing supramolecular sheet-like multilayer molecular packing stabilized by $\mathrm{C}-\mathrm{H}$...O interactions (Table S2) involving the phenyl and acryloyl hydrogen with the carbonyl oxygen and the alkoxy oxygen atoms (Fig. 4). The molecules of compound $\mathbf{C 1}$ are connected to each other by the cyclic $\mathrm{R}_{2}{ }_{2}(8)$ type of $\mathrm{C}-\mathrm{H}$... O hydrogen bond motifs.

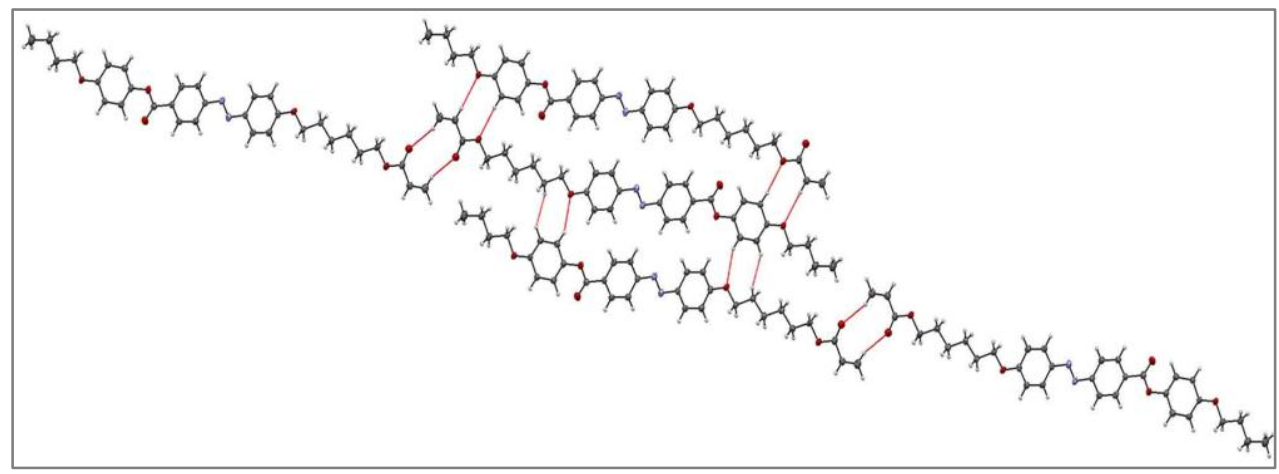

Fig. 4. Crystal structure of compound $\mathbf{C} \mathbf{1}$ with the hydrogen bond motifs. 


\subsection{Thermal and mesophase behaviour}

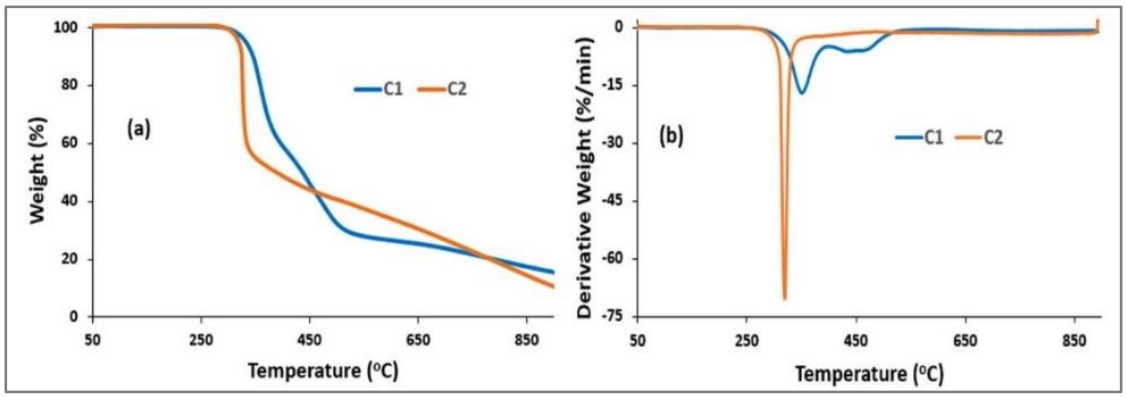

Fig. 5. (a) TG and (b) DTG curves of compounds C1-C2 recorded at a heating rate of $20{ }^{\circ} \mathrm{C} \mathrm{min}-1$ under nitrogen atmosphere.

The thermogravimetric investigations were performed in order to study the decomposition patterns as well as thermal stability of the synthesized compounds and all the measurements were made in a temperature range of $50-900{ }^{\circ} \mathrm{C}$ under nitrogen atmosphere. The TG and DTG curves of compounds C1-C2 are depicted in Fig. 5. The thermal decomposition temperatures at $5 \%\left(T_{\mathrm{d}}\right)$ weight loss for both of the compounds are above $316{ }^{\circ} \mathrm{C}$ and these results indicate that the thermal stability of the investigated compounds are very high [32]. Compound $\mathbf{C 1}$ exhibited two-stage thermal decomposition while $\mathbf{C 2}$ showed single-stage decomposition. The first stage decomposition of $\mathbf{C 1}$ was started around $264-284{ }^{\circ} \mathrm{C}$ and completed about $352-400{ }^{\circ} \mathrm{C}$ with estimated mass loss of $36-51 \%$. These cleavages may be due to the thermal decomposition of azo group, long alkyl chain and terminal substituents located in the mesogen [33-35]. On the other hand, the second stage decomposition of $\mathbf{C} 1$ was taken place about $352-556{ }^{\circ} \mathrm{C}$ and a mass loss of $13-35 \%$ was observed in this stage. This decomposition may be ascribed to the thermal degradation of heat resistant aromatic moiety [36]. On the contrary, 46.5\% mass loss happened around $282-357{ }^{\circ} \mathrm{C}$ for compound $\mathbf{C 2}$. This result may be attributed to thermal break down of azo linking group, long alkyl chain and terminal heavy halogen atom (iodo) located in the mesogen. Furthermore, $44 \%$ weight loss was observed gradually until $900{ }^{\circ} \mathrm{C}$ due to the thermal degradation of heat resistant aromatic moiety.

Table 1. Phase transition and enthalpy changes for compounds C1-C2 upon heating and cooling scans.

\begin{tabular}{|c|c|c|c|c|}
\hline \multirow{2}{*}{ Comp. } & \multirow{2}{*}{\multicolumn{2}{|c|}{ Phase transitions $\left({ }^{\circ} \mathrm{C}\right)$ (enthalpy changes, $\mathrm{J} \mathrm{g}^{-1}$ ) }} & \multicolumn{2}{|c|}{ Mesophase range $\left({ }^{\circ} \mathrm{C}\right)$} \\
\hline & & & $\mathrm{SmA}$ & $\mathrm{N}$ \\
\hline \multirow[t]{2}{*}{ C1 } & 2nd Heating & Cr 102.3 (63.6) SmA 162.1 (0.2) N 199.2 (0.7) I & \multirow[b]{2}{*}{95.3} & \multirow[b]{2}{*}{38.3} \\
\hline & 1st Cooling & $\begin{array}{l}\text { Cr } 65.3(-65.8) \text { SmA } 160.6(-0.4) \text { N } 198.9(-1.1) \\
\text { I }\end{array}$ & & \\
\hline $\mathrm{C2}$ & $\begin{array}{l}\text { 1st Heating } \\
1 \text { st Cooling }\end{array}$ & $\begin{array}{l}\text { Cr } 137.9 \text { (37.2) SmA } 199.8(3.7) \mathrm{I} \\
\mathrm{Cr} 124.5(-26.4) \mathrm{SmA} 196.9(-0.5) \mathrm{I}\end{array}$ & 71.4 & - \\
\hline
\end{tabular}

Transition temperatures $\left({ }^{\circ} \mathrm{C}\right)$ and enthalpy changes (in parentheses, $\mathrm{J} \mathrm{g}^{-1}$ ) were measured by DSC at the heating and cooling rates of $10{ }^{\circ} \mathrm{C} \mathrm{min}^{-1}$. $\mathrm{Cr}=$ Crystalline phase; $\mathrm{SmA}=$ Smectic A phase; $\mathrm{N}=$ Nematic phase; $\mathrm{I}=$ Isotropic liquid. 


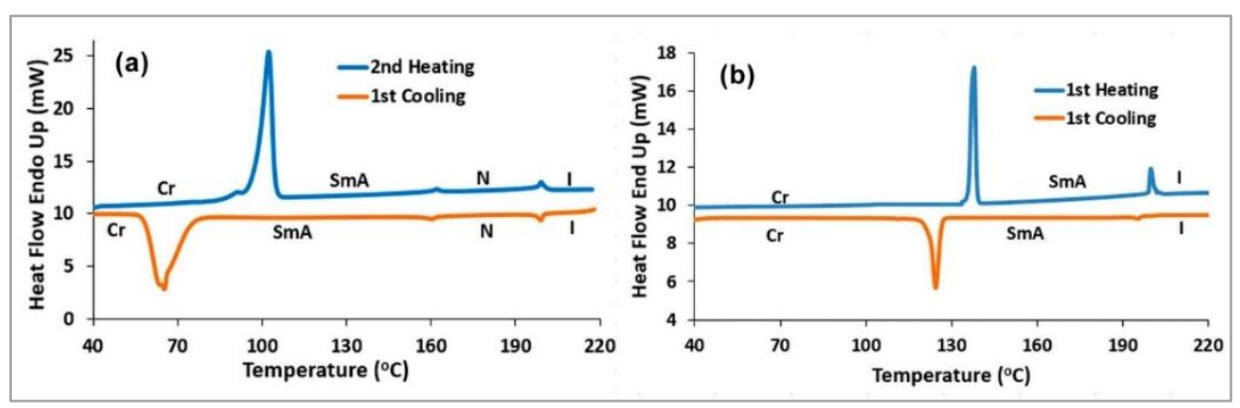

Fig. 6. DSC thermograms of compounds (a) $\mathbf{C 1}$ and (b) $\mathbf{C 2}$ upon heating and cooling scans at the rate of $\pm 10^{\circ} \mathrm{C} \mathrm{min}^{-1}$.

The mesophase behaviour of compounds C1-C2 was studied by differential scanning calorimetry (DSC) and polarized optical microscope (POM). Phase transition temperatures and associated enthalpy changes of the synthesized compounds are summarized in Table 1. The DSC thermograms of compounds C1-C2 are depicted in Fig. 6. In the second heating process, compound $\mathbf{C 1}$ exhibited an endothermic thermal transition at $102.3{ }^{\circ} \mathrm{C}$, representing melting of the compound. Smectic to nematic transition occurred at $162.1{ }^{\circ} \mathrm{C}$ while nematic to an orderless isotropic change was happened at $199.2^{\circ} \mathrm{C}$. During cooling scan, $\mathbf{C 1}$ also showed three thermal transitions: (i) isotropic to nematic transition at $198.9{ }^{\circ} \mathrm{C}$, (ii) nematic to smectic at $160.6{ }^{\circ} \mathrm{C}$ and (iii) smectic to crystallization at $65.3{ }^{\circ} \mathrm{C}$. The nematic and smectic transitions occurred during both of heating and cooling scans, indicating an enantiotropic phase transition of compound C1. However, compound $\mathbf{C 2}$ exhibited two thermal transitions: (i) crystal to smectic at $137.9{ }^{\circ} \mathrm{C}$ and (ii) smectic to isotropic at $199.8^{\circ} \mathrm{C}$ during first heating cycle. However, no well-defined thermal transition peaks were observed during second heating process for compound $\mathbf{C 2}$. This outcome may be due to the presence of heavy halogen atom (iodine) which could induce partial decomposition of the mesogenic core during second heating process. As a result, first heating data were evaluated for further discussion [37]. On the other hand, isotopic to smectic transition occurred at $196.9^{\circ} \mathrm{C}$ and crystallization happened at $124.5{ }^{\circ} \mathrm{C}$ upon cooling scan. Compound $\mathbf{C 2}$ showed enantiotropic thermal transitions upon heating and cooling scans as observed in C1.
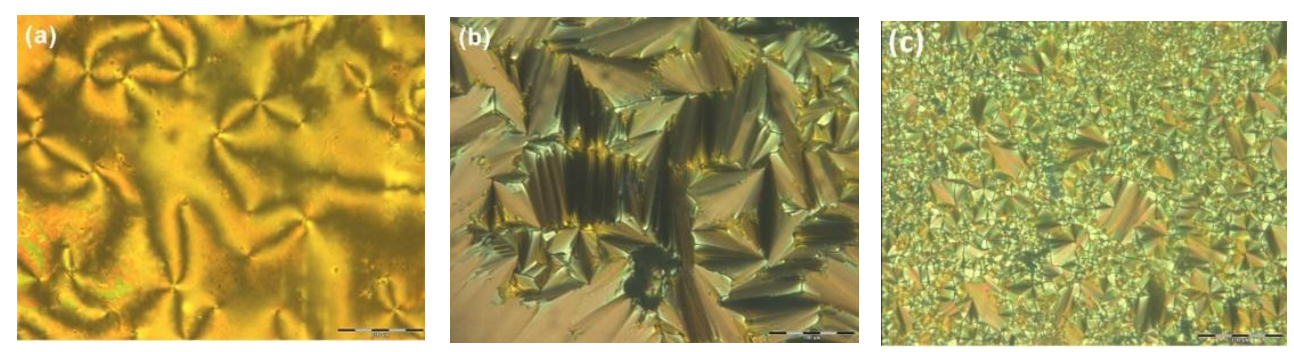

Fig. 7. POM images of compound C1-C2 upon cooling from isotropic liquid: (a) $\mathbf{C 1}$ at $198.9{ }^{\circ} \mathrm{C}$ and (b) $\mathbf{C 1}$ at $160.6^{\circ} \mathrm{C}$; (c) $\mathbf{C 2}$ at $196.9^{\circ} \mathrm{C}$. All the optical micrographs were taken with a magnification of $50 \times$. 
The polarized optical micrographs of C1-C2 are presented in Fig. 7. The identification of nematic and smectic phases was made by comparing the observed textures with those reported in the literatures [38,39]. The POM observations also revealed that both compounds exhibited enantiotropic phase transitions during heating and cooling cycles. On cooling from isotropic liquid, compound $\mathbf{C 1}$ revealed schlieren texture of nematic phase with four-fold brush at $198.9^{\circ} \mathrm{C}$ and fan-shaped texture of SmA phase at $160.6{ }^{\circ} \mathrm{C}$ (Fig. 7a-b). Conversely, compound $\mathbf{C 2}$ only showed focal conic texture characteristic of SmA mesophase at $196.9^{\circ} \mathrm{C}$ (Fig. 7c) upon cooling from isotropic melt. Compound C2 exhibited only SmA phase, however, compound $\mathbf{C 1}$ with a longer terminal carbon chain formed both nematic and SmA phases. This phase behavior is expected for rod-like molecules [40]. The phase transition temperatures evaluated on the basis of texture change are in good accord with those measured by DSC. It can be seen form Table 1 and Fig. 6 that the mesophase stability (temperature range of the mesophase) of compounds C1-C2 was greatly influenced by the terminal substituents $\left(-\mathrm{OC}_{4} \mathrm{H}_{9}\right.$, and $\left.-\mathrm{I}\right)$. The butoxy terminated compound $\mathbf{C 1}$ exhibited greater mesophase stability than that of heaver halogen atom iodine (I) containing compound C2. This outcome may be explained on the basis that the lone pair electrons of oxygen in $-\mathrm{OC}_{4} \mathrm{H}_{9}$ group are shielded by an insulatorlike butyl group. The repulsive forces between the lone pairs of oxygen in different molecules are thereby significantly reduced and allow a close approach of the neighboring molecules, increasing bonding forces. As a result, total mesophase stability of C1 increases substantially [41]. Moreover, elongation of the overall molecular length by increasing the carbon length on the other side of terminal chain led to the formation of more ordered SmA phases beside for nematic phase at higher temperature. This can probably be attributed to an enhanced dispersive interaction between the terminal alkoxy chains [40]. The lesser mesophase stability of compound C2 may be due to the heavier size and reduced polarizing power of iodine atom [42].

\subsection{Optical properties}

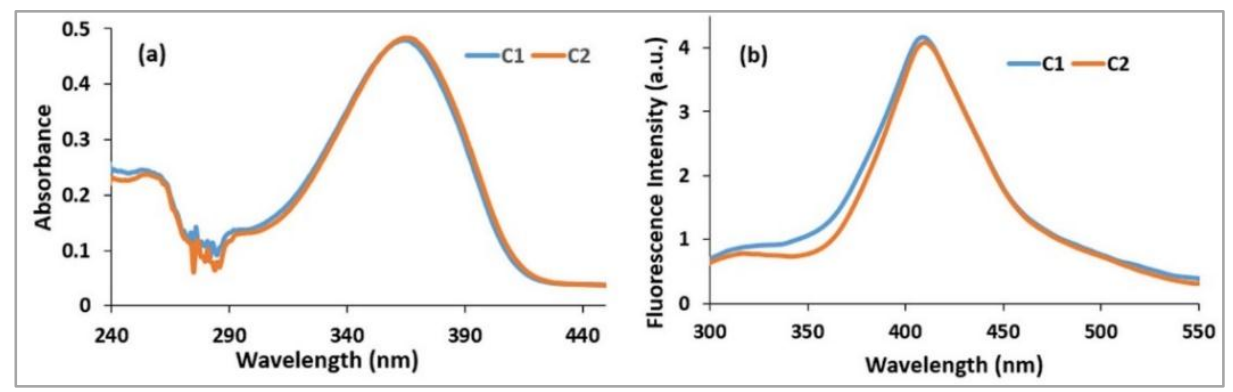

Fig. 8. (a) UV-vis and (b) PL spectra of compounds $\mathbf{C 1 - C 2}$ in dilute $\mathrm{CHCl}_{3}$ solutions $\left(1 \times 10^{-5} \mathrm{M}\right)$.

The UV-vis absorption spectra of compounds C1-C2 in dilute chloroform solutions are presented in Fig. 8a. As both of the compounds bear structural similarity except the terminal group, the absorption spectra are very similar in shape. A shoulder liked 
absorption band appeared around 250-265 nm and this band may be attributed to a $\pi-\pi^{*}$ transition of the phenyl rings [43-45]. The broad absorption bands of the investigated compounds were found about $300-420 \mathrm{~nm}$ with absorption maximum $\left(\lambda_{\max }\right)$ of nearly 365 $\mathrm{nm}$. This band can be regarded as a $\pi-\pi^{*}$ transition involving the $\pi$-electronic system throughout the whole molecule with a considerable charge transfer (CT) character [46]. Fig. 8b exhibits fluorescence spectra of C1-C2 in dilute $\mathrm{CHCl}_{3}$ solution $\left(1 \times 10^{-5} \mathrm{M}\right)$ and the emission spectra were also found identical pattern like absorption spectra due to the structural similarities in the mesogenic unit of both compounds. The fluorescence emission maxima of C1-C2 are located around $410 \mathrm{~nm}$ which may be categorized as blue emission. The observed fluorescence intensities of compounds C1-C2 were not significant compared with standard compound pyrene. This result could be due to the presence of photochromic azo group in the mesogenic core of compounds C1-C2. Most of the azo compounds exhibit efficient reversible cis-trans photoisomerism upon absorption of photon within the absorption band which quenched or suppressed fluorescence emission in solution [47]. However, no significant effect of terminal groups was observed on UVvis and fluorescence spectra of compounds.

\section{Conclusion}

In the present study, azo-ester linked mesogen containing two LC compounds C1-C2 with polymerizable acrylate terminal group were synthesized and characterized. X-ray crystal structure showed that compound $\mathbf{C 1}$ exhibited stable $E$ configuration at the $\mathrm{N}=\mathrm{N}$ double bond motifs. The molecules of compound $\mathbf{C 1}$ are connected to each other by means of cyclic $\mathrm{R}_{2}^{2}(8)$ type of $\mathrm{C}-\mathrm{H}$... O hydrogen bond motifs. Both of the compounds exhibited excellent thermal stability under TGA observation. The mesophase formation as well as mesophase stability of investigated compounds was influenced by the terminal substituents. Absorption and PL studies revealed that both compounds showed a broad absorption band around 300-420 $\mathrm{nm}$ and blue emission nearly 350-500 $\mathrm{nm}$.

\section{Acknowledgement}

The authors would like to thank University of Malaya for the financial support during this work.

\section{References}

1. R. J. Carlton, J. T. Hunter, D. S. Miller, R. Abbasi, P. C. Mushenheim, L. N. Tan, and N. L. Abbott, Liq. Cryst. Rev. 1, 29 (2013). https://doi.org/10.1080/21680396.2013.769310

2. G. P. Crawford, S. J. Woltman, and G. D. Jay, Liquid Crystals: Frontiers in Biomedical Applications (World Scientific, Singapore, 2007). https://doi.org/10.1142/9789812778871_0001

3. O. M. S. Ritter, N. P. D. Silveira, and A. A., Merlo, J. Braz. Chem. Soc. 17, 348 (2006). https://doi.org/10.1590/S0103-50532006000200019 
4. H. S. Nalwa, Handbook of Advanced Electronic and Photonic Materials and Devices: Liquid Crystals, Display and Laser Materials (Academic Press, 2001).

5. W. L. He, M. Li, S. Q Liu, M. J. Wei, C. Liu, L.L. Li, Z. Yang, D. Wang, and H. Cao, Liq. Cryst. 45, 370 (2018). https://doi.org/10.1080/02678292.2017.1330430

6. N. S. F Dzulkharnien, N. M. Salleh, R. Yahya, and M. R. Karim, Soft Mater 15, 292 (2017). https://doi.org/10.1080/1539445X.2017.1355816

7. S. Singh, and D. A. Dunmur, Liquid Crystals: Fundamentals (World Scientific, 2002). https://doi.org/10.1142/4369

8. P. O. Åstrand, P. S. Ramanujam, S. Hvilsted, K. L. Bak, and S. P. A. Sauer, J. Am. Chem. Soc. 122, 3482 (2000). https://doi.org/10.1021/ja993154r

9. X. Zhang, C. Wang, X. Lu and Y. Zeng, Optik. 123, 26 (2012). https://doi.org/10.1016/j.ijleo.2010.09.053

10. N. Tabiryan, U. Hrozhyk, and S. Serak, Phys. Rev. Lett. 93, 113901 (2004). https://doi.org/10.1103/PhysRevLett.93.113901

11. U. A. Hrozhyk, S. V. Serak, N. V. Tabiryan, L. Hoke, D. M. Steeves, and B. R. Kimball, Opt. Express. 18, 8697 (2010). https://doi.org/10.1364/OE.18.008697

12. W. M. Gibbons, P. J. Shannon, S. T. Sun, and B. J. Swetlin, Nature 351, 49 (1991). https://doi.org/10.1038/351049a0

13. L. D. Sio, L. Ricciardi, S. Serak, M. L. Deda, N. Tabiryan, and C. Umeton, J. Mater. Chem. 22 , 6669 (2012). https://doi.org/10.1039/c2jm16077c

14. X. Li, L. Fang, L. Hou, L. Zhu, Y. Zhang, B. Zhang, and H. Zhang, Soft Matter 8, 5532 (2012). https://doi.org/10.1039/c2sm25163a

15. Y. Wang, Y. Liao, C. P. Cabry, D. Zhou, G. Xie, Z. Qu, D. W. Bruce, and W. Zhu, J. Mater. Chem. C. 5, 3999 (2017). https://doi.org/10.1039/C7TC00034K

16. M. R. Karim, M. R. K. Sheikh, N. M. Salleh, R. Yahya, A. Hassan and M. A. Hoque, Mater. Chem. Phys. 140, 543 (2013). https://doi.org/10.1016/j.matchemphys.2013.04.003

17. S. K. Prasad, G. G. Nair, and D. S. S. Rao, Liq. Cryst. 36, 705 (2009). https://doi.org/10.1080/02678290902755572

18. G. Pavlovic', L. Racane', H. Cicăk, and V. T. Kulenovic, Dyes Pigments 83, 354 (2009). https://doi.org/10.1016/j.dyepig.2009.06.002

19. Hunger K. Rev. Prog. Coloration 29, 71 (1999). https://doi.org/10.1111/j.1478-4408.1999.tb00129.x

20. B. T. Thaker and J. B. Kanojiya, Liq. Cryst. 38, 1035 (2011). https://doi.org/10.1080/02678292.2011.594525

21. M. C. Varia, S. Kumar, and A. K. Prajapati, Liq. Cryst. 39, 365 (2012). https://doi.org/10.1080/02678292.2012.657696

22. R. A. Vora and N. Dixit, Mol. Cryst. Liq. Cryst. 59, 63 (1980).

23. L. L Lai and H. C. Lin, Liq. Cryst. 27, 707 (2000). https://doi.org/10.1080/026782900202606

24. C. T. Imrie, P. A. Henderson, and G. Y. Yeap, Liq. Cryst. 36, 755 (2009). https://doi.org/10.1080/02678290903175267

25. M. M. Naoum, A .A. Fahmi, N. H. S. Ahmed, and G. R. Saad, Liq. Cryst. 42, 1627 (2015).

26. M. M. Naoum, N. H. Metwally, M. M. A. Eltawab, and H. A. Ahmed, Liq. Cryst. 42, 1351 (2015). https://doi.org/10.1080/02678292.2015.1049567

27. M. R. Karim, M. R. K. Sheikh, R. Yahya, N. M. Salleh, K. M. Lo, and H. N. M E. Mahmud, Liq. Cryst. 43, 1862 (2016). https://doi.org/10.1080/02678292.2016.1216620

28. V. Prasad, Liq. Cryst. 28, 145 (2001). https://doi.org/10.1080/026782901462481

29. J. H. Liu, C. D. Hsieh, and H. Y. Wang, J. Polym. Sci. A 42, 1075 (2004). https://doi.org/10.1002/pola.11070

30. M. Gür, H. Kocaokutgen, and M. Tasx, Dyes Pigments 72, 101 (2007). https://doi.org/10.1016/j.dyepig.2005.08.005 
31. J. Geng, T. Tao, S. J. Fu, W. You, and W. Huang, Dyes Pigments 90, 65 (2011). https://doi.org/10.1016/j.dyepig.2010.11.008

32. J. W. Y. Lam, X. Kong, Y. Dong, K. K. L. Cheuk, K. Xu, and B. Z. Tang, Macromolecules 33, 5027 (2000). https://doi.org/10.1021/ma992097j

33. B. K Chen, Y. S Tsay, and J. Y Chen, Polymer 46, 8624 (2005). https://doi.org/10.1016/j.polymer.2005.06.084

34. H. W. Zhao, X. Z. He, J. J. Zheng, W. L. Song, F. B. Meng, and J. S. Hu, Liq. Cryst. 44, 2379 (2017). https://doi.org/10.1080/02678292.2017.1335894

35. M. R. Karim, R, Yahya, M. R. K. Sheikh, N, M. Salleh, A. Hassan, and H. N. M. E. Mahmud, J. Polym. Res. 21, 487 (2014). https://doi.org/10.1007/s10965-014-0487-3

36. Y. Cui, G. Qian, L. Chen, Z. Wang, and M. Wang, Dyes Pigments 77, 217 (2008). https://doi.org/10.1016/j.dyepig.2007.05.005

37. N. G. Nagaveni, A. Roy, and V. Prasad, J. Mater. Chem. 22, 8948 (2012). https://doi.org/10.1039/c2jm30709j

38. D. Demus and L. Richter, Textures of Liquid Crystals, $2^{\text {nd }}$ Edition (Verlag Chemie, New York, 1978).

39. I. Dierking, Textures of Liquid Crystals (John Wiley \& Sons Incorporated, UK, 2003). https://doi.org/10.1002/3527602054

40. C. S. Wang, I. W. Wang, K. L. Cheng, and C. K. Laia, Tetrahedron 62, 9383 (2006). https://doi.org/10.1016/j.tet.2006.07.058

41. B. T. Thaker, J. B. Kanojiya, and R. S. Tandel, Mol. Cryst. Liq. Cryst. 528, 120 (2010). https://doi.org/10.1080/15421406.2010.504632

42. F. Karipcin, E. Kabalcilar, S. Ilican, Y. Caglar, and M. Caglar, Spectrochim. Acta A 73, 174 (2009). https://doi.org/10.1016/j.saa.2009.02.012

43. T. K. Pal, M. A. Alam, J. Hossen, S. Paul, H. Ahmad, and M. C. Sheikh, J. Sci. Res. 10, 291 (2018). https://doi.org/10.3329/jsr.v10i3.36379

44. E. H. Ismail, D. Y. Sabry, H. Mahdy, and M. M. H. Khalil, J. Sci. Res. 6, 509 (2014). https://doi.org/10.3329/jsr.v6i3.18750

45. M. R. Karim, M. R. K. Sheikh, R. Yahya, N. M. Salleh, and A. D. Azzahari, Colloid Polym. Sci. 293, 1923 (2015). https://doi.org/10.1007/s00396-015-3578-8

46. K. Rameshbabu and P. Kannan, Liq. Cryst. 31, 843 (2004). https://doi.org/10.1080/02678290410001703127

47. C. J. Barrett, J. I. Mamiya, K. G. Yager, and T. Ikeda, Soft Matter 3, 1249 (2007). https://doi.org/10.1039/b705619b 